\title{
Student and instructor attitudes toward CALL and MALL in the L2 classroom
}

\section{Pagel, James W'a Lambacher, Stephen ${ }^{\text {b }}$; Kikuchi, Hisayo and Moric, Sachiho ${ }^{\text {a }}$}

${ }^{\mathrm{a} C}$ College of Science and Engineering, Aoyama Gakuin University, Japan; ${ }^{\mathrm{b}}$ School of Social Informatics, Aoyama Gakuin University, Japan; ${ }^{\mathrm{c}}$ School of Global Studies and Collaboration, Aoyama Gakuin University, Japan.

\begin{abstract}
As part of an ongoing study focusing on language learner and instructor attitudes toward the use of computers and mobile devices in second language (L2) learning contexts, the authors attempt to identify to what degree language instructors value the use of computers and mobile devices in their teaching. We compare the responses of a survey administered to an "inhouse" group of instructors within two faculties of a private university in Tokyo, Japan, with the responses collected from a similar survey administered to instructors solicited through various CALL organizations. The number of respondents of the "in-house" survey during the first three years was relatively low; however, in the final year was considerably much higher, with the number from both full-time and part-time staff totaling 34. The total number of survey respondents from the CALL organizations totaled 121, with the participants' places of employment ranging from Europe to the Asia Pacific Rim. In addition to offering an interpretation of a sampling of the Likert scale items found on the surveys, the authors focus on comparing the responses offered by both groups of instructors regarding which skills they focused on in the CALL classroom, as well as what mobile applications they encouraged their students to use.
\end{abstract}

Keywords: survey analyses, intrinsic motivation, mobile applications, adoption of mobile technologies 


\section{Introduction}

The incorporation of computer-assisted language learning (CALL) and mobile-assisted language learning (MALL) technologies by foreign language educators worldwide has significantly altered the role of the teacher, leading to a validation of Kurzweil's prediction that "education will advance from 2009, with students using computers nearly exclusively for learning, with teachers available as motivators," (Kurzweil, 2000). However, as language education surges forward, does the incorporation of these technologies benefit the learner or simply satisfy the instructor's need to be innovative? Also, why are some teachers still hesitant to incorporate these potentially effective technologies? The main goal of this study is to try to answer these questions as a way to help gain a better understanding of the current and future states of ICT technologies and methodologies, and how they can be more effectively utilized to improve foreign language education. We attempt to achieve this goal by administering two surveys - the first survey to English language instructors employed at our university in Tokyo, and the second survey to CALL practitioners living and working at universities in Europe and the Pacific Rim region. Our main goal is to gauge the attitudes of instructors regarding their use of CALL and MALL technologies in teaching English as a second/foreign language. We were also interesting in finding out the most commonly used applications being used by instructors and whether they were having a positive impact on their students' language learning in and out of the classroom. Additionally, we focus on ascertaining what the main obstacles are that prevent educators from embracing these rapidly advancing technologies.

MALL has indeed emerged as the next generation of e-Learning. One reason for this is due to the high availability of mobile devices worldwide. The smaller screen size and touch interface of smartphones and tablets also leads to a more concentrated learning, as the student typically has running in the background just a single program at any given time, as opposed to the more common multitasking operations found on desktop and notebook PCs (Gualtieri, 2011). MALL is motivating to learners to improve foreign language skills, as it offers them a rich, informal, contextual, and ubiquitous learning environment. Mobile learning technologies are rapidly gaining popularity around the world as an effective way to enhance foreign language learning education. M-learning is motivating to learners because it offers rich, informal, contextual, and ubiquitous learning environment for learners to control their time, environment, and speed. The use of mobile technologies for language learning purposes has numerous advantages over other methods, for example, the countless number of English news programs, language learning apps, podcasts, and videos that are easily accessible and free or reasonably priced. Web-based resources using Web 2.0 tools and mobile computing technologies can be easily integrated to promote collaborative learning activities. 
In second language (L2) learning, and in CALL in particular, there has been an increasing body of research dedicated to the use of mobile devices in language learning over the past several years. Teachers and researchers use the term MALL as if it were familiar to everyone in the field. It is not our intention here to trace the roots of MALL and its place in language learning today (see Stockwell (2012) for a more detailed discussion). Instead, our purpose here as educators is to try to determine whether mobile-assisted learning holds benefits for our students, to see how and why students come to use this technology, and how mobile learning compares with more traditional classroom approaches.

Much prior research has focused on how CALL compares with more traditional classroom approaches; see in particular Levy and Stockwell (2013), both of whom give exhaustive coverage to this important area but in different eras. The literature on learning using mobile devices and student reactions - other than criticism as it pertains to the devices' limitations, size and thus readability (see Chinnery, 2006) — is still rather limited, as publications to date tend to describe the types of devices used, e.g., PDAs, cell phones, etc., and outcomes expected.

During the past five years at Aoyama Gakuin University (AGU) in Tokyo we have surveyed both our students and instructors annually within two schools - the College of Science and Engineering and the School of Social Informatics, respectively. A key motivating factor for this research has been the total revamping of one of our school's English curriculum, which went into effect in April 2012. The surveys were thus developed to serve as part of a faculty development endeavor to evaluate instructor reactions to the new curriculum, which required all classes be held in CALL classrooms and for instructors to adapt their teaching methods to take full advantage of the available facilities and technology. The total number of student respondents from both schools has averaged nearly 350 annually. Our "in-house" teaching faculty has been comprised of nine full-time and 26 part-time instructors across the two schools.

\section{Method}

\subsection{International Survey}

The surveys were created using SurveyMonkey®. The "international" survey was comprised of 42 questions based on Likert scale five-item response type (1 "Strongly Disagree" to 5 "Strongly Agree"). We targeted organizations comprised of CALL practitioners. The survey was distributed to volunteers solicited through the LinkedIn ${ }^{\mathrm{TM}}$ CALL page (i.e., targeting EUROCALL membership) and direct solicitations made to JALTCALL and APACALL membership through their respective organizations. All survey responses from the CALL organizations totaled 121. The respondents' employment locations, as could be expected given the sources tapped, ranged from Europe to Asia, including Japan and other Asia Pacific Rim countries, with a few exceptions. In terms of 
age, the respondents were equally distributed in the 30s, 40s, and 50s. Male respondents outnumbered females $57 \%$ to $43 \%$. Additionally, $80.9 \%$ of the respondents were employed as full-time instructors engaged in L2 teaching.

\subsection{In-house Survey}

The In-house survey was comprised of 32 questions of the same Likert scale five-item response type. The survey was administered four times over a four-year period. To ensure anonymity, all questions regarding personal information, such as age and nationality, were eliminated. The number of teaching staff of the two faculties currently totals 34 . While the total number of respondents participating during the first three years averaged only 16 , this number increased in the final year due to an increase in the number of instructors employed within both faculties as a result of an expanded English curriculum.

\section{Results}

\subsection{Survey $(C A L L)$}

Table 1. Mean ratings for survey items related CALL.

\begin{tabular}{|c|c|c|c|}
\hline & Mean rating & Std Deviation & Sig. \\
\hline \multicolumn{4}{|c|}{ CALL technology is readily available at my university. } \\
\hline In-house & 4.4 & .79 & \multirow{2}{*}{$p<.05$} \\
\hline International & 3.7 & 1.13 & \\
\hline \multicolumn{4}{|c|}{ I feel comfortable using CALL. } \\
\hline In-house & 3.5 & .89 & \multirow{2}{*}{$p=.938$} \\
\hline International & 4.3 & .90 & \\
\hline \multicolumn{4}{|c|}{ Using CALL is not worth the trouble. } \\
\hline In-house & 2.3 & .95 & \multirow{2}{*}{$\mathrm{p}=.723$} \\
\hline International & 1.9 & 1.08 & \\
\hline \multicolumn{4}{|c|}{ I require my students to use CALL for learning English. } \\
\hline In-house & 3.9 & .96 & \multirow{2}{*}{$\mathrm{p}=.129$} \\
\hline International & 3.6 & 1.08 & \\
\hline \multicolumn{4}{|c|}{ My students enjoy using CALL technology to learn English compared with traditional methods } \\
\hline In-house & 3.5 & .72 & \multirow{2}{*}{$p=.204$} \\
\hline International & 3.7 & .88 & \\
\hline \multicolumn{4}{|c|}{ Using CALL technology has improved my students' English skills } \\
\hline In-house & 3.5 & .80 & \multirow{2}{*}{$\mathrm{p}=.173$} \\
\hline International & 3.9 & .77 & \\
\hline
\end{tabular}


Table 1 shows the mean response ratings of a select number of survey items related to CALL. We were interested in gauging both groups' attitudes toward their use of CALL in the classroom. Overall, a significant difference was exhibited in how both groups responded to the item "CALL technology is readily available at my university," with the "in-house" group responding higher than the "international" group (4.4 vs. 3.7). Conversely, the "international" group was more confident than the "in-house" group in their comfort level using CALL (4.3 vs. 3.5), albeit a nonsignificant difference. In response to "Using CALL is not worth the trouble," the "in-house" group agreed slightly more than the "international" group (2.3 vs. 1.9). As shown above, both groups' mean ratings were somewhat high for the following three items related to using CALL for English language learning: "I require my students to use CALL for learning English during class," "Using CALL technology has improved my students' English skills," and "My students enjoy using CALL technology to learn English compared to traditional methods." However, it should be pointed that some of the responses indicated that facilities were not available for students on campus from universities outside of Japan.

\subsection{Survey $(M A L L)$}

Table 2 MALL-related survey items.

\begin{tabular}{|c|c|c|c|}
\hline & Mean rating & Std Deviation & Sig. \\
\hline \multicolumn{4}{|c|}{ I use a mobile device to facilitate my own foreign language learning. } \\
\hline In-house & 3.4 & 1.21 & \multirow{2}{*}{$\mathrm{p}=.61$} \\
\hline International & 3.5 & 1.29 & \\
\hline \multicolumn{4}{|c|}{ I feel comfortable using MALL technology. } \\
\hline In-house & 3.3 & .89 & \multirow{2}{*}{$\mathrm{p}<.05$} \\
\hline International & 4.8 & 1.11 & \\
\hline \multicolumn{4}{|c|}{ Using MALL is not worth the trouble. } \\
\hline In-house & 2.4 & .95 & \multirow{2}{*}{$p=.075$} \\
\hline International & 2.4 & 1.27 & \\
\hline \multicolumn{4}{|c|}{ My students enjoy using MALL technology to learn English. } \\
\hline In-house & 3.4 & .67 & \multirow{2}{*}{$\mathrm{p}=.227$} \\
\hline International & 4.6 & .80 & \\
\hline \multicolumn{4}{|c|}{ Using MALL technology has improved my students' English skills. } \\
\hline In-house & 3.3 & .64 & \multirow{2}{*}{$p<.01$} \\
\hline International & 4.4 & .96 & \\
\hline
\end{tabular}

Table 2 shows both groups' responses to a select number of MALL-related items. As shown, the "international" group was significantly more confident in using MALL than the 
"in-house" group (4.8 vs. 3.4). In response to "Using MALL is not worth the trouble" both groups were equally divided (2.5 vs. 2.4). In response to the two items "Using MALL technology has improved my students' English skills" and "My students enjoy using MALL technology to learn English," the "international" group was substantially higher than the "in-house" group (4.4 and 4.7 vs. 3.3 and 3.4, respectively).

Another area of concern was the type of applications instructors recommended and the ones the students actually used. The responses were very disparate and non-specific - dictionary and social networking were common responses. This may indicate the respondents misinterpreted the two questions - "what applications do you recommend" and "which do you observe your students using." Despite the ambiguity of the responses, the applications commonly recommended can be categorized as "vocabulary," "dictionary," "testing, "comprehensive" (inclusive), "management," and "social networking" in descending order. The applications instructors observed their students using were similar, with the inclusion of "radio." In future surveys, the authors will rephrase the questions so as to elicit more accurate responses. However, the authors want to emphasize that the instructor's role in guiding the students to worthwhile applications is crucial. Students may have mastered technology, but they are apt to use the easiest, most common applications available. It also should be pointed out that more than a few of the international respondents commented that they were unaware of available mobile applications, with one commenting that mobile learning was inappropriate for lower level students. Such comments stood out but were clearly not in the majority. See Ali and Miraz (2018) for a brief survey of language learning applications implemented on mobile computing devices.

Our final area of inquiry was to ascertain the skills that instructors focus on with their students using mobile devices and computers. The overall pattern of responses for both groups (shown below in percentages, averaged across both groups) were similar concerning mobile devices, with the following skills preferred: vocabulary (82\%), listening $(77 \%)$, and reading $(67 \%)$, with pronunciation (44\%), writing (36\%), speaking $(28 \%)$ and grammar (26\%) receiving substantially fewer responses. In contrast, the response patterns for skills when using computers were less congruent. For example, the "international" group favored listening $(80 \%)$, reading $(76 \%)$, and vocabulary $(71 \%)$, followed by writing $(67 \%)$ and speaking $(60 \%)$, while the "in-house" group preferred listening (85\%), writing (69\%), reading $(65 \%)$, and vocabulary $(58 \%)$. Overall, both groups emphasized receptive over productive skills when using mobile devices, although with computers the tendency was to focus on both receptive and productive skills.

\section{Discussion and Conclusion}

Overall, the results revealed that both groups' attitudes towards CALL and MALL varied. The "international" group felt more comfortable and positive using CALL and MALL 
compared to the "in-house" group. Similarly, the "international" group was more in agreement that MALL can be effectively utilized to improve students' language skills and that their students enjoyed using mobile devices to study English. These results should come as no surprise, since a majority of the "international" participants were CALL specialists, while "in-house" participants included a significant number of non-CALL practitioners. Moreover, a majority of the "in-house" respondents lacked experience in using MALL. An unexpected result was both groups responded similarly to questions about CALL technology and language learning, as both were positive with regard to its impact on their students' English acquisition and satisfaction and preference for it compared to traditional methods, as also noted by Stockwell (2012) in his analysis of how CALL stacks up with traditional classroom approaches. We are hard-pressed to provide a sensible explanation for this particular response by the "in-house" group. One possible reason could be that since all "in-house" instructors were required to conduct their classes in CALL classrooms and strongly encouraged to use the available technology, some may have felt inclined to respond more positively than they would have otherwise. The results also showed that vocabulary, dictionary, and testing apps were the most commonly recommended apps. Additionally, both groups emphasized receptive over productive skills, at least when their students utilized mobile devices.

After careful review of the instructors' individual comments regarding the MALL section, it was apparent their students did not possess nearly the same number of mobile devices as the "in-house" Japanese students, hence the fewer responses regarding MALL applications. In short, if no mobile devices or applications are available, then none will be used. However, the international instructors did indicate that they would use additional applications should they become available.

\section{Future directions}

Our plan is to continue to examine student and instructor attitudes towards mobile devices used in L2 learning environments. However, the Japanese Ministry of Education, Culture, Sports, Science and Technology has recently been focusing its efforts on adopting the Common European Framework of Reference (CEFR) to assess both student and instructor levels of communication skills as they fit into language classes starting at the middle school level (MEXT, 2012). This plan is referred as the "English Education Reform Plan Corresponding to Globalization." As this move will have a significant impact within our own institution, we are in the process of investigating the recognition and implementation of CEFR at institutions in Japanese and around the Pacific Rim, as well as reviewing the standing of CEFR within its European home base. 


\section{References}

Ali, M., \& Miraz, S. K. (2018). Mobile Assisted Language Learning (MALL)-A Brief Survey. Annals of Emerging Technologies in Computing (AETiC), 2 (2), pp.37-45.

Chinnery, G. (2006). Going to the MALL: Mobile assisted-learning. Language Learning and Technology, 10 (1), pp-9-16.

Gardner, R. (2007). Motivation and second language acquisition. Porta Linguarum, 8, pp.920.

Gualtieri, M. (2011, April). Mobile app design best practices: When it comes to designing the mobile user experience (UX), context is king. Retrieved from http://www.forrester.com/rb/Research/mobile_app_design_best_practices/q/id/59132/t/2

Kurzweil, R. (2000). The age of spiritual machines: When computers exceed human intelligence. New York: Penguin.

Levy, M. (1997). Computer-Assisted Language Learning: Context and Conceptualization. New York: Oxford University Press.

Levy, M., \& Stockwell, G. (2013). CALL dimensions: Options and issues in computerassisted language learning. Routledge.

MEXT, Japanese Ministry of Education, Culture, Sports, Science and Technology (2012). http://www.mext.go.jp/b_menu/shingi/chousa/shotou/082/houkoku/1308375.htm (last accessed November 11, 2017).

Stockwell, G. (ed.) (2012). Computer-assisted language learning: Diversity in research and practice. Cambridge: Cambridge University Press. 